\title{
Amino Acid Concentrations and Protein Metabolism of Two Types of Rat Skeletal Muscle in Postprandial State and After Brief Starvation
}

\author{
M. HOLEČEK ${ }^{1}$, S. MIČUDA ${ }^{2}$ \\ ${ }^{1}$ Department of Physiology, Faculty of Medicine in Hradec Kralove, Charles University, Hradec \\ Kralove, Czech Republic, ${ }^{2}$ Department of Pharmacology, Faculty of Medicine in Hradec Kralove, \\ Charles University, Hradec Kralove, Czech Republic
}

Received March 24, 2017

Accepted May 11, 2017

On-line September 22, 2017

\section{Summary}

We have investigated amino acid concentrations and protein metabolism in musculus extensor digitorum longus (EDL, fasttwitch, white muscle) and musculus soleus (SOL, slow-twitch, red muscle) of rats sacrificed in the fed state or after one day of starvation. Fractional protein synthesis rates (FRPS) were measured using the flooding dose method ( $\mathrm{L}-[3,4,5-3 \mathrm{H}]$ phenylalanine). Activities of two major proteolytic systems in muscle (the ubiquitin-proteasome and lysosomal) were examined by measurement of chymotrypsin like activity of proteasome (CTLA), expression of ubiquitin ligases atrogin-1 and muscle-ring-finger-1 (MuRF-1), and cathepsin B and L activities. Intramuscular concentrations of the most of non-essential amino acids, FRPS, CTLA and cathepsin B and L activities were in postprandial state higher in SOL when compared with EDL. The differences in atrogin-1 and MuRF-1 expression were insignificant. Starvation decreased concentrations of a number of amino acids and increased concentrations of valine, leucine, and isoleucine in blood plasma. Starvation also decreased intramuscular concentrations of a number of amino acids differently in EDL and SOL, decreased protein synthesis (by $31 \%$ in SOL and $47 \%$ in EDL), and increased expression of atrogin-1 and MuRF-1 in EDL. The effect of starvation on CTLA and cathepsin $B$ and $L$ activities was insignificant. It is concluded that slow-twitch (red) muscles have higher rates of protein turnover and may adapt better to brief starvation when compared to fast-twitch (white) muscles. This phenomenon may play a role in more pronounced atrophy of white muscles in aging and muscle wasting disorders.

\section{Key words}

Red and white muscle • Amino acids • Starvation • Atrogens • Branched-chain amino acids

\section{Corresponding author}

M. Holeček, Department of Physiology, Faculty of Medicine in Hradec Kralove, Charles University, Simkova 870, 50003 Hradec Kralove, Czech Republic. Tel./Fax: +420-495816335. E-mail: holecek@lfhk.cuni.cz

\section{Introduction}

There are two basic types of skeletal muscle fibers, which differ in both physical and biochemical properties (Gupta et al. 1989). In general, type I fibers have small diameter, more capillaries, contain higher levels of mitochondria and myoglobin, and their twitch rate is slower and more prolonged than type II fibers. Due to these properties, type I fibers are also called red or slow-twitch fibers. Among muscles predominantly composed by red fibers belong muscles of breathing and large back muscles, which are necessary for maintaining posture, and muscles used for walking, such as soleus muscle. Type II fibers, called also white, glycolytic, or fast-twitch fibers, are thicker. Their contraction is stronger and faster, muscle glycogen serves as the primary source of energy, and their resistance to fatigue is lower than that of fibers type I. High content of type II fibers is in muscles which ensure delicate and rapid movements, such as muscles of the eye and musculus extensor digitorum longus. 
A number of reports demonstrate that muscles composed mostly by white fibers are more sensitive to catabolic stimuli, particularly to sepsis, when compared to muscles with high content of red fibers (Holecek et al. 2015, Holecek et al. 2014, Kovarik et al. 2012, Tiao et al. 1997, Safranek et al. 2006, Muthny et al. 2008). Also with advancing age there is a preferential loss and atrophy of white fibers with a preservation of red fibers (Evans 2010). However, the explanation of origin of these clinically important differences in response of red and white fibers to signals causing the loss of muscle is not available.

Food intake and a brief starvation are undoubtedly the most frequent conditions, which affect protein and amino acid metabolism in muscles. Food intake activates pathways of protein synthesis and inhibits proteolysis; brief starvation is associated with increased release of amino acids from muscles, which are used preferentially for gluconeogenesis. It may be hypothesized that differences to respond to food intake and to starvation play a role in differences in alterations in protein balance of white and red muscles during muscle wasting conditions. However, to the best of our knowledge, no study has so far been done on the effects of starvation in this context.

The main objective of the present study was to examine the differences in parameters of protein metabolism and amino acid levels in musculus extensor digitorum longus (EDL, fast-twitch, white muscle) and musculus soleus (SOL, slow-twitch, red muscle) of rats in postprandial state and after a brief starvation. We measured fractional rates of protein synthesis and the activities of two major proteolytic systems within the cells (the ubiquitin-proteasome and lysosomal pathways). In addition, we examined expression of mRNAs of atrogin-1 and muscle-ring-finger-1 (MuRF-1), two E3 ubiquitin ligases (termed atrogenes) that are important regulators of ubiquitin-mediated protein degradation, which is recognized as the main proteolytic pathway for degradation of structural proteins of muscle tissue (Wing 2005).

\section{Materials and Methods}

\section{Animals and material}

Male Wistar rats (BioTest, Konarovice, Czech Republic) were housed in standardized cages in quarters with controlled temperature and a 12-h light-dark cycle. All rats received the standard laboratory diet ST-1 (Velaz,
Czech Republic) and drinking water ad libitum. All procedures involving animals were performed according to the guidelines set by the Institutional Animal Care and Use Committee of Charles University. Animal Care and Use Committee of Charles University, Faculty of Medicine in Hradec Kralove specifically approved this study. L-[3,4,5- $\left.{ }^{3} \mathrm{H}\right]$ phenylalanine was purchased from American Radiolabeled Chemical, Inc. (St. Louis, MO, USA). Chemicals were obtained from Sigma Chemical (St. Louis, MO, USA), Lachema (Brno, Czech Republic), and Waters (Milford, MA, USA).

\section{Experimental design}

A total of 40 male Wistar rats weighing approximately $200 \mathrm{~g}$ each were randomly divided into two groups. Half of the animals in each group were sacrificed in pentobarbital narcosis $(6 \mathrm{mg} / 100 \mathrm{~g}$ body weight, intraperitoneally) by exsanguination from the abdominal aorta in the fed state, and the other half after one day of starvation. Afterwards, small pieces (approximately $0.1 \mathrm{~g}$ ) of soleus (SOL) and extensor digitorum longus (EDL) muscles were quickly removed and frozen in liquid nitrogen.

Two separate studies were performed. Alterations in amino acid concentrations in blood plasma, SOL, and EDL muscles, and various parameters of protein breakdown were examined in the first study. Tissue protein synthesis rates were measured using the flooding dose method (L- $\left[3,4,5-{ }^{3} \mathrm{H}\right]$ phenylalanine) in the second study.

\section{Amino acid concentrations in blood plasma and muscles}

Amino acid concentrations were determined in the supernatants of deproteinized blood plasma and tissue samples using high-performance liquid chromatography (Aliance 2695, Waters, Milford, MA, USA) after derivatization with 6-aminoquinolyl-N-hydroxysuccinimidyl carbamate. The intracellular concentration of each amino acid in samples of muscle tissues was calculated by subtracting the free extracellular portion from the total amount, assuming the plasma concentration to be equal to the concentration in the interstitial fluid as described by Bergström et al. (1974). Total tissue water was measured from the tissue weight obtained after drying for $24 \mathrm{~h}$ at $90{ }^{\circ} \mathrm{C}$. The determination of extra- and intracellular water was based on the chloride method according to Graham et al. (1967). 
Chymotrypsin-like activity (CTLA)

The chymotrypsin-like activity of proteasomes was determined using the fluorogenic substrate Suc-LLVY-MCA (Gomes-Marcondes and Tisdale 2002) as follows. The muscles were homogenized in $0.4 \mathrm{ml}$ of ice-cold $20 \mathrm{mM}$ Tris buffer, $\mathrm{pH} 7.5$, containing $2 \mathrm{mM}$ ATP, $5 \mathrm{mM} \mathrm{MgCl}_{2}$ and $1 \mathrm{mM}$ dithiothreitol. The homogenates were centrifuged for $10 \mathrm{~min}$ at $18,000 \times \mathrm{g}$ at $4{ }^{\circ} \mathrm{C}$. Cellular supernatants $(0.1 \mathrm{ml})$ were incubated with $0.1 \mathrm{ml}$ of substrate Suc-LLVY-MCA $(0.1 \mathrm{mM})$ with or without inhibitor MG132 $(0.02 \mathrm{mM})$ for $1 \mathrm{~h}$ on ice. A volume of $0.4 \mathrm{ml}$ of $100 \mathrm{mM}$ sodium acetate buffer (pH 4.3) was added to stop the reaction. Sample fluorescence was immediately determined at an excitation wavelength of $340 \mathrm{~nm}$ and emission wavelength of $440 \mathrm{~nm}$ (Tecan Infinite ${ }^{\mathrm{TM}} 200$ ). The standard curve was established for 7-amino-4-methylcoumarin (AMC), which permitted the expression of CTLA as nmol of $\mathrm{AMC} / \mathrm{g}$ protein/h. Differences after the subtraction of inhibited from non-inhibited activities were used for calculations. The activity was adjusted for the protein concentration of the supernatant.

\section{Cathepsin B and L activities}

The activities of cathepsin B and L were determined using the fluorogenic substrate Z-FA-MCA (Koohmaraie and Kretchmar 1990, Tardy et al. 2004) as follows. Tissue samples (approximately $20 \mathrm{mg}$ ) were homogenized in $0.6 \mathrm{ml}$ of ice-cold $300 \mathrm{mM}$ sodium acetate buffer, $\mathrm{pH} 5.0$, containing $4 \mathrm{mM}$ EDTA, $8 \mathrm{mM}$ dithiothreitol and $0.2 \%$ Triton X-100 (v/v). The homogenates were allowed to stand for $30 \mathrm{~min}$ on ice and centrifuged for $30 \mathrm{~min}$ at $18,000 \times \mathrm{g}$ at $4{ }^{\circ} \mathrm{C}$. Cellular supernatant $(0.01 \mathrm{ml})$ were incubated with $0.19 \mathrm{ml}$ of substrate Z-FA-MCA $(0.1 \mathrm{mM})$ with or without the inhibitor Z-FF-FMK $(0.04 \mathrm{mM})$ for $30 \mathrm{~min}$ at $37^{\circ} \mathrm{C}$. The reaction was stopped by the addition of $1 \mathrm{ml}$ of $100 \mathrm{mM}$ sodium acetate buffer, $\mathrm{pH} 4.3$, and the activities of cathepsin $\mathrm{B}$ and $\mathrm{L}$ were determined as described above for CTLA.

\section{Real time RT-PCR analysis}

Expression of atrogin-1 (Fbxo32), and MuRF-1 mRNA was examined using qRT-PCR on 7500HT Fast Real-Time PCR System (Applied Biosystems, Foster City, USA). Total RNA was isolated from rat skeletal muscles using TRIzol reagent (Invitrogen, USA) and converted into cDNA via High Capacity cDNA reverse transcription kit (Applied Biosystems, Foster City, USA). Reaction mixture contained $30 \mathrm{ng}$ of analyzed cDNA. The amplification of each sample was performed in triplicate using TaqMan ${ }^{\circledR}$ Fast Universal PCR Master Mix (Applied Biosystems, Foster City, USA). Atrogin-1 and MuRF-1 quantitative PCR (qPCR) assays were designed and optimized in GENERI BIOTECH s.r.o. (Hradec Kralove, Czech Republic) as shown in Table 1. The time-temperature profile used in the "fast" mode was: $95^{\circ} \mathrm{C}$ for $3 \mathrm{~min} ; 40$ cycles: $95^{\circ} \mathrm{C}$ for $7 \mathrm{~s}, 60^{\circ} \mathrm{C}$ for $25 \mathrm{~s}$. For normalization, two reference genes were selected using the geNorm according to Vandesompele et al. (2002), GAPDH (4352338E, Applied Biosystems, Foster City, USA), and Ywhaz (GENERI BIOTECH s.r.o., Hradec Kralove, Czech Republic), as shown in Table 1. Expression values of each sample were obtained as described previously (Radilova et al. 2009). Briefly, the expression data were normalized by the geometric mean of GAPDH, and Ywhaz expressions. Finally, the relative expression between control and affected tissue was determined by comparison of normalized data.

Table 1. Quantitative PCR assays for reference gene and target genes provided by GENERI BIOTECH.

\begin{tabular}{lccc}
\hline Gene symbol & qPCR assay & Reference sequence & Exons spanned \\
\hline Ywhaz (reference gene) & rYwhaz_Q1 & NM_013011 & exon5/exon6 \\
Fbxo32 (Atrogin-1) & rFbxo32_Q2 & NM_133521 & exon8/exon9 \\
Trim63 (MuRF-1) & rTrim63_Q3 & NM_080903 & exon8/exon9 \\
\hline
\end{tabular}

\section{Protein synthesis}

The rats were injected intravenously with a flooding dose of $\mathrm{L}-\left[3,4,5-{ }^{3} \mathrm{H}\right]$ phenylalanine $(50 \mu \mathrm{Ci} /$ $100 \mathrm{~g}$ b.w.) combined with unlabelled L-phenylalanine
(150 $\mu \mathrm{mol} / 100 \mathrm{~g}$ b.w.) $10 \mathrm{~min}$ before the sacrifice by exsanguination via the abdominal aorta (Garlick et al. 1980). Tissue samples were homogenized in $6 \%(\mathrm{v} / \mathrm{v})$ perchloric acid, and the precipitated proteins were 
collected via centrifugation for $5 \mathrm{~min}$ at $12,000 \times \mathrm{g}$. The supernatant was used for the measurement of L- $\left[3,4,5-{ }^{3} \mathrm{H}\right]$ phenylalanine specific activity. The pellet was washed three times and hydrolyzed in $2 \mathrm{~N} \mathrm{NaOH}$. Aliquots were taken for protein content (Lowry et al. 1951) and radioactivity measurements. The fractional rate of protein synthesis (FRPS) was calculated according the formula derived by McNurlan et al. (1979):

$$
\operatorname{FRPS}(\% \text { per day })=\left(\mathrm{S}_{\mathrm{b}} \cdot 100\right) /\left(\mathrm{t} \cdot \mathrm{S}_{\mathrm{a}}\right)
$$

where $S_{b}$ and $S_{a}$ are the specific activities (dpm/nanomole) of protein-bound phenylalanine and tissue-free phenylalanine in the acid-soluble fraction of tissue homogenates, respectively, and $t$ is the time (days) between isotope injection and tissue immersion into liquid nitrogen. The value of $274 \mu \mathrm{mol}$ phenylalanine/g protein was used for the calculation of protein-bound phenylalanine specific activity (Welle 1999). Sample radioactivity was measured using a liquid scintillation radioactivity counter LS 6000 (Beckman Instruments, Fullerton, CA, USA).

\section{Statistics}

The results are expressed as the means $\pm \mathrm{SE}$. F-test followed by paired t-test (to estimate the differences between EDL and SOL obtained from the same animal) and unpaired t-test (to estimate the effects of starvation on the specific muscle type) have been used for the analysis of the data. Differences were considered significant at $\mathrm{P}<0.05$. NCSS 2001 statistical software (Kaysville, UT, USA) was used for the analyses.

\section{Results}

\section{Amino acid concentrations in blood plasma}

Starvation for $24 \mathrm{~h}$ decreased blood plasma concentrations of histidine, methionine, alanine, arginine, ornithine, and proline, whereas concentrations of all three branched-chain amino acids (BCAA; valine, isoleucine, and leucine) increased (Table 2).

\section{Amino acid concentrations in muscles}

Table 3 demonstrates that intramuscular concentrations of histidine and lysine and of the most of non-essential amino acids were in postprandial state higher in SOL when compared with EDL. More than double were the concentrations of aspartate, asparagine, and glutamate. Lower concentrations in SOL than in EDL exhibited glycine and threonine.

Starvation decreased intramuscular concentrations of a number of essential (histidine, lysine, and threonine in EDL; the BCAA and methionine in SOL) and non-essential (alanine, arginine, glycine, ornithine, proline, and serine in EDL; alanine, ornithine, and proline in SOL) amino acids. The exceptions observed in both muscle types were increased concentrations of aspartate and glutamate.

Table 2. Effect of a brief starvation on amino acid concentrations in blood plasma.

\begin{tabular}{|c|c|c|}
\hline & $\begin{array}{c}\text { Control } \\
(n=10)\end{array}$ & $\begin{array}{c}\text { Starvation } \\
\quad(n=10)\end{array}$ \\
\hline \multicolumn{3}{|l|}{$\boldsymbol{E} \boldsymbol{A} \boldsymbol{A}$} \\
\hline Histidine & $70 \pm 1$ & $58 \pm 4^{*}$ \\
\hline Isoleucine & $84 \pm 3$ & $112 \pm 2^{*}$ \\
\hline Leucine & $134 \pm 6$ & $160 \pm 3^{*}$ \\
\hline Lysine & $283 \pm 9$ & $356 \pm 15$ \\
\hline Methionine & $49 \pm 1$ & $44 \pm 1^{*}$ \\
\hline Phenylalanine & $65 \pm 1$ & $64 \pm 1$ \\
\hline Threonine & $256 \pm 6$ & $255 \pm 10$ \\
\hline Valine & $174 \pm 7$ & $200 \pm 4^{*}$ \\
\hline$\Sigma B C A A$ & $392 \pm 16$ & $472 \pm 9^{*}$ \\
\hline$\Sigma E A A$ & $1,115 \pm 19$ & $1,250 \pm 22^{*}$ \\
\hline \multicolumn{3}{|l|}{$N E A A$} \\
\hline Alanine & $528 \pm 20$ & $309 \pm 12^{*}$ \\
\hline Arginine & $127 \pm 5$ & $113 \pm 2^{*}$ \\
\hline Asparagine & $62 \pm 3$ & $54 \pm 2$ \\
\hline Aspartate & $18 \pm 2$ & $16 \pm 2$ \\
\hline Citrulline & $83 \pm 2$ & $77 \pm 2$ \\
\hline Glutamate & $87 \pm 4$ & $97 \pm 3$ \\
\hline Glutamine & $642 \pm 16$ & $665 \pm 13$ \\
\hline Glycine & $310 \pm 17$ & $423 \pm 18$ \\
\hline Ornithine & $51 \pm 1$ & $43 \pm 2^{*}$ \\
\hline Proline & $226 \pm 8$ & $112 \pm 3^{*}$ \\
\hline Serine & $237 \pm 9$ & $243 \pm 9$ \\
\hline Taurine & $274 \pm 29$ & $285 \pm 33$ \\
\hline Tyrosine & $87 \pm 4$ & $81 \pm 6$ \\
\hline$\Sigma N E A A$ & $2,816 \pm 71$ & $2,604 \pm 66^{*}$ \\
\hline$\Sigma$ Amino acids & $3,932 \pm 66$ & $3,853 \pm 80$ \\
\hline
\end{tabular}

Values are in $\mu \mathrm{mol} / \mathrm{l}$. Means $\pm \mathrm{SE} . * \mathrm{P}<0.05$. BCAA, branchedchain amino acids; EAA, essential amino acids; NEAA, non-essential amino acids. 
Table 3. Amino acid concentrations in EDL and SOL of rats in postprandial state and after brief starvation.

\begin{tabular}{|c|c|c|c|c|}
\hline & \multicolumn{2}{|c|}{ Postprandial state } & \multicolumn{2}{|c|}{ Starvation for $24 \mathrm{~h}$} \\
\hline & $\operatorname{EDL}(n=10)$ & SOL $(n=10)$ & EDL $(n=10)$ & SOL $(n=10)$ \\
\hline \multicolumn{5}{|l|}{$\boldsymbol{E} \boldsymbol{A} \boldsymbol{A}$} \\
\hline Histidine & $430 \pm 19$ & $781 \pm 71^{*}$ & $323 \pm 13 \#$ & $606 \pm 45^{*}$ \\
\hline Isoleucine & $127 \pm 6$ & $124 \pm 5$ & $146 \pm 8$ & $119 \pm 10^{*}$ \\
\hline Leucine & $224 \pm 11$ & $231 \pm 9$ & $223 \pm 14$ & $193 \pm 17^{*} \#$ \\
\hline Lysine & $1,103 \pm 54$ & $1,323 \pm 88^{*}$ & $857 \pm 58 \#$ & $1,318 \pm 116^{*}$ \\
\hline Methionine & $75 \pm 7$ & $82 \pm 5$ & $78 \pm 5$ & $62 \pm 5^{* \#}$ \\
\hline Phenylalanine & $110 \pm 5$ & $108 \pm 4$ & $111 \pm 5$ & $95 \pm 7 *$ \\
\hline Threonine & $1,235 \pm 33$ & $1,107 \pm 4^{*}$ & $1,116 \pm 40 \#$ & $1,052 \pm 42$ \\
\hline Valine & $311 \pm 10$ & $300 \pm 14$ & $277 \pm 15$ & $223 \pm 19$ *\# \\
\hline$\Sigma B C A A$ & $662 \pm 27$ & $656 \pm 27$ & $646 \pm 37$ & $534 \pm 45^{*} \#$ \\
\hline$\Sigma E A A$ & $3,615 \pm 67$ & $4,057 \pm 179^{*}$ & $3,130 \pm 137 \#$ & $3,668 \pm 218^{*}$ \\
\hline \multicolumn{5}{|l|}{$N E A A$} \\
\hline Alanine & $3,732 \pm 199$ & $4,019 \pm 228$ & $2,919 \pm 163 \#$ & $3,403 \pm 196^{* \#}$ \\
\hline Arginine & $583 \pm 34$ & $691 \pm 59^{*}$ & $367 \pm 27 \#$ & $543 \pm 60^{*}$ \\
\hline Asparagine & $367 \pm 19$ & $773 \pm 67^{*}$ & $407 \pm 11$ & $847 \pm 52 *$ \\
\hline Aspartate & $461 \pm 25$ & $2,094 \pm 202 *$ & $583 \pm 62 \#$ & $4,659 \pm 284^{* \#}$ \\
\hline Citrulline & $571 \pm 27$ & $736 \pm 48^{*}$ & $521 \pm 23$ & $807 \pm 46^{*}$ \\
\hline Glutamate & $2,255 \pm 157$ & $5,606 \pm 326^{*}$ & $3,609 \pm 180 \#$ & $6,430 \pm 303^{*}$ \\
\hline Glutamine & $9,225 \pm 484$ & $12,005 \pm 702 *$ & $8,256 \pm 343$ & $12,333 \pm 467^{*}$ \\
\hline Glycine & $7,195 \pm 374$ & $4,176 \pm 322 *$ & $6,009 \pm 397 \#$ & $4,329 \pm 155^{*} \#$ \\
\hline Ornithine & $111 \pm 4$ & $143 \pm 10^{*}$ & $54 \pm 3 \#$ & $105 \pm 10 * \#$ \\
\hline Proline & $758 \pm 18$ & $856 \pm 65$ & $429 \pm 20 \#$ & $403 \pm 24 \#$ \\
\hline Serine & $1,932 \pm 95$ & $3,563 \pm 262 *$ & $1,457 \pm 37 \#$ & $3,241 \pm 145^{*}$ \\
\hline Taurine & $25,278 \pm 811$ & $34,124 \pm 1,198^{*}$ & $26,887 \pm 1,014$ & $35,500 \pm 1,300^{*}$ \\
\hline Tyrosine & $204 \pm 8$ & $189 \pm 7$ & $232 \pm 9 \#$ & $191 \pm 12^{*}$ \\
\hline$\Sigma N E A A$ & $52,672 \pm 1,416$ & $68,976 \pm 2,627 *$ & $51,729 \pm 1,323$ & $72,791 \pm 2,609^{*}$ \\
\hline$\Sigma$ Amino acids & $56,287 \pm 1,454$ & $73,034 \pm 2,771 *$ & $54,860 \pm 1,413$ & $76,459 \pm 2,739 *$ \\
\hline
\end{tabular}

Values are in $\mu \mathrm{mol} / \mathrm{l}$ of intracellular fluid. Means $\pm \mathrm{SE} . \mathrm{P}<0.05 . *$ Effects of muscle type (paired-t test, compared muscles of the same animals); \# effect of starvation (unpaired t-test, comparison to corresponding type of muscle of fed animals). BCAA, branched-chain amino acids; EAA, essential amino acids; NEAA, non-essential amino acids.

Protein synthesis and proteolysis

Fractional rates of protein synthesis, CTLA and cathepsin $\mathrm{B}$ and $\mathrm{L}$ activities in muscles of fed animals were higher in SOL compared to EDL muscles. Starvation decreased protein synthesis both in SOL and EDL (by $31 \%$ and $47 \%$, respectively). The effect of starvation on CTLA and cathepsin B and L activities was insignificant (Figs 1, 2 and 3).

\section{Atrogenes}

There were no differences between SOL and EDL in mRNA expression of atrogin-1 and MuRF-1 in muscles obtained from fed animals. Starvation increased expression of both ubiquitin ligases in EDL, whereas the effect on SOL was insignificant (Figs 4 and 5).

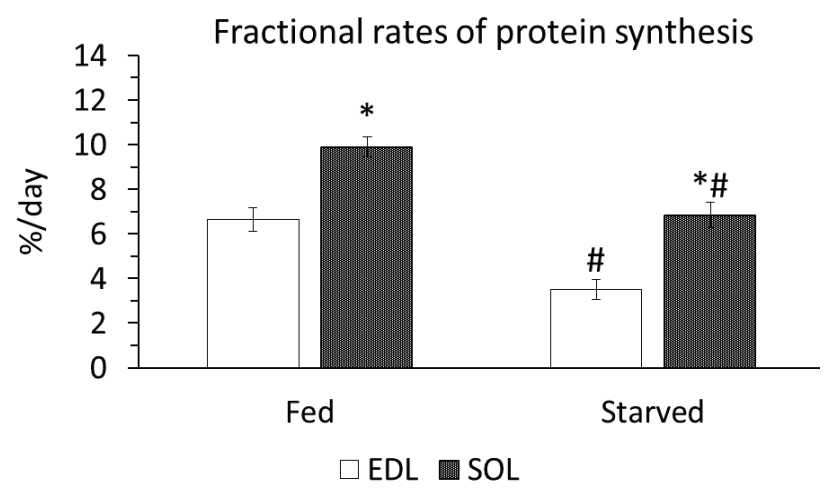

Fig. 1. Fractional rates of protein synthesis (FRPS) in EDL and SOL of fed and one day starving rats. Means \pm SE $(n=10) . P<0.05$. * Effects of muscle type (paired-t test, compared muscles of the same animals); \# effect of starvation (unpaired t-test, comparison to corresponding type of muscle of fed animals). 


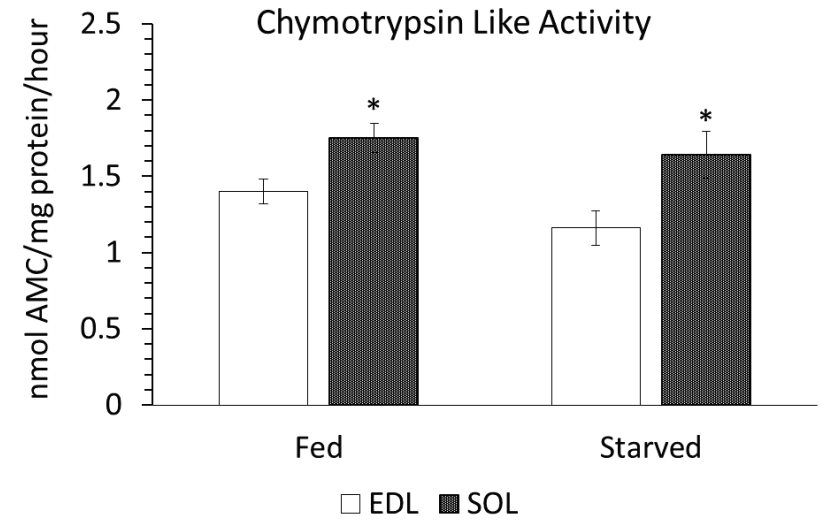

Fig. 2. Chymotrypsin like activity (CTLA) in EDL and SOL of fed and one day starving rats. Means $\pm S E(n=10) . P<0.05$. * Effects of muscle type (paired-t test, compared muscles of the same animals); \# effect of starvation (unpaired t-test, comparison to corresponding type of muscle of fed animals).

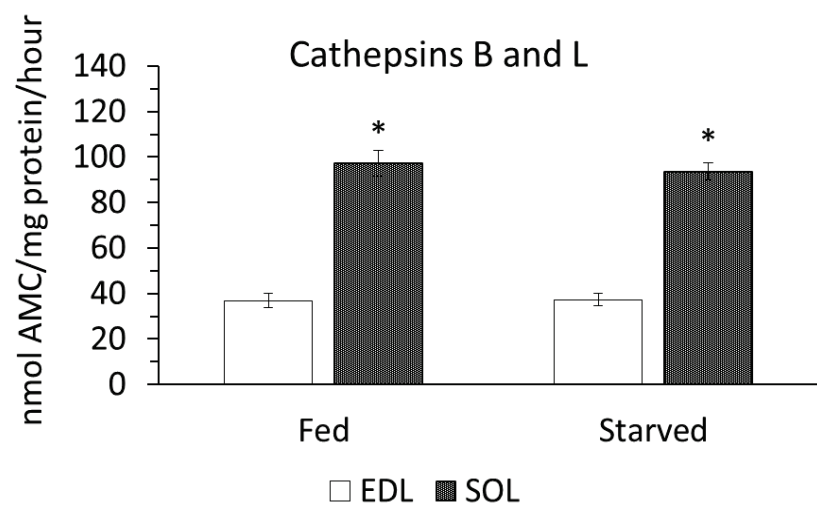

Fig. 3. Cathepsin $B$ and $L$ activities in EDL and SOL of fed and one day starving rats. Means \pm SE $(n=10)$. $P<0.05$. * Effects of muscle type (paired-t test, compared muscles of the same animals); \# effect of starvation (unpaired t-test, comparison to corresponding type of muscle of fed animals).

\section{Discussion}

The differences in amino acid concentrations and protein metabolism in postprandial state

Higher concentrations of histidine and lysine and of the most of non-essential amino acids in SOL (slowtwitch) compared with EDL (fast-twitch) muscle are in agreement with our previous study (Holecek and Sispera 2016) and with Turinsky and Long (1990), who reported higher concentrations of a number of amino acids in SOL when compared with other types of fast twitch muscles (plantaris and gastrocnemius muscles). Also the observations of higher FRPS, CTLA and cathepsin B and $\mathrm{L}$ activities in SOL when compared to EDL is in agreement with other studies (Holecek and Sispera 2014, Garlick et al. 1989). Greater CTLA activities in SOL are consistent with higher release of 3-methyhistidine

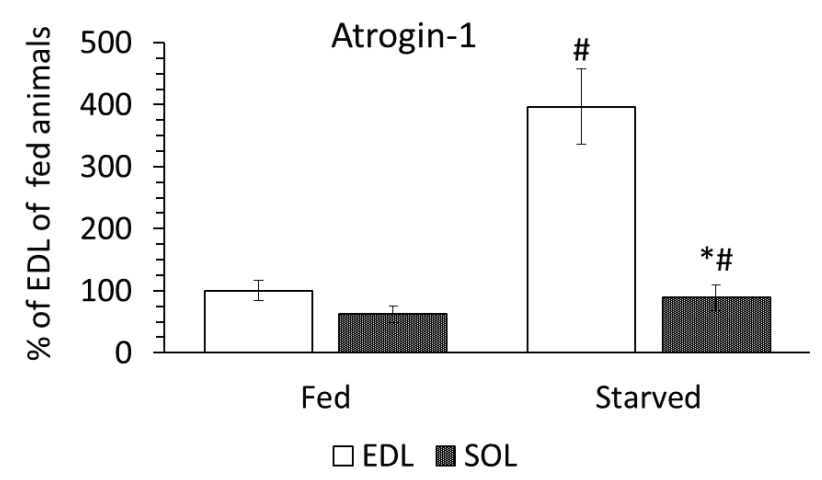

Fig. 4. Expression of $m R N A$ of atrogin- 1 in $E D L$ and $S O L$ of fed and one day starving rats. Means \pm SE $(n=10) . P<0.05$. * Effects of muscle type (paired-t test, compared muscles of the same animals); \# effect of starvation (unpaired t-test, comparison to corresponding type of muscle of fed animals).

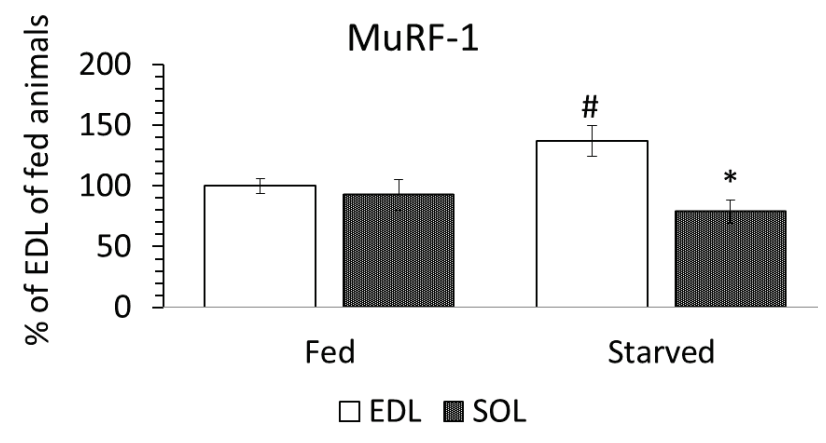

Fig. 5. Expression of mRNA of MuRF-1 in EDL and SOL of fed and one day starving rats. Means $\pm \operatorname{SE}(n=10) . P<0.05$. * Effects of muscle type (paired-t test, compared muscles of the same animals); \# effect of starvation (unpaired t-test, comparison to corresponding type of muscle of fed animals).

(marker of degradation of myofibrillar proteins) from isolated SOL to incubation medium when compared with EDL (Holecek and Sispera 2014, Muthny et. al 2009, Muthny et. al 2008).

We assume that higher intracellular levels of amino acids and rates of protein synthesis and proteolysis in SOL than EDL indicate more appropriate conditions of red muscles for adaptation to various physiological and pathological conditions affecting muscle protein balance, such as starvation and muscle wasting disorders.

Effects of brief starvation on amino acid concentrations in blood plasma and muscles

Characteristic features of a brief starvation are accelerated release of amino acids from muscles and augmentation of gluconeogenesis in the liver, which are caused mostly by reduced insulin and increased glucagon 
levels. Activated gluconeogenesis is undoubtedly the main cause of the decreased concentration of a number of amino acids in blood plasma of starved rats. The cause of the unique increase in all three BCAA (valine, leucine, and isoleucine) is not clear. In our opinion, a role have their enhanced release from muscles, reduced uptake due to decreased insulin production, and increased BCAA synthesis from branched-chain keto acids in the liver, which may be activated in various catabolic conditions (Holecek et al. 2001, Holecek 2001).

The observed decrease of a number of amino acids in muscles is mostly due to their enhanced release, activated catabolism, and decreased uptake from the blood. Increased levels of glutamate and aspartate in muscles of starving animals indicate draining of alphaketoglutarate and oxaloacetate from tricarboxylic acid cycle (cataplerosis) to act as the main acceptor of amino nitrogen released in amino acid catabolism, notably of the BCAA. Glutamate synthesized from alpha-ketoglutarate may be used for ammonia detoxification to glutamine or as the donor of nitrogen for synthesis of alanine, the amino acid released in exceptionally high amounts from the muscles during a brief starvation. Aspartate formed from oxaloacetate may be used for synthesis of nucleotides.

The main differences in amino acid concentrations induced by brief starvation in EDL and SOL were a decrease in a larger number of non-essential amino acids in EDL and the decrease in the BCAA in SOL. Unfortunately, we do not have explanation for origin of these differences. A role may have lower amino acid concentrations in white muscles, different sensitivity of white and red fibers to decreased ratio of insulin to glucagon, etc.

\section{Effects of brief starvation on protein metabolism}

Increased release of amino acids from skeletal muscle during starvation is associated with protein loss, which can be caused by decreased protein synthesis, increased breakdown or both. An early event in starvation is a decline in muscle protein synthesis, whereas increased rates of protein breakdown may be observed when starvation is prolonged (Stirewalt et al. 1985, Jepson et al. 1986, Goodman et al. 1981).

More pronounced decrease in protein synthesis in EDL compared to SOL observed in our study indicates that a brief starvation impairs protein balance more in white than in red fibers. Higher suppression of protein synthesis in EDL compared to SOL was found also under in vitro conditions in muscles of animals with sepsis induced by cecal ligation and puncture (Holecek et al. 2015), endotoxin treatment (Kovarik et al. 2010), and with turpentine-induced inflammation (Muthny et al. 2008).

We did not see effect of a one-day starvation on CTLA and activities of B and L cathepsins in any of the two muscles. However, a great increase in expression of atrogin-1 and MuRF-1 genes was found in EDL. Atrogin-1 and MuRF-1 are upregulated in various experimental models of muscle atrophy, including starvation, and their substrate targets are regulatory and contractile muscle proteins (Foletta et al. 2011, Bodine and Baehr 2014). Overexpression of atrogin-1 in myotubes produced atrophy, whereas mice deficient in either atrogin-1 or MuRF-1 were found to be resistant to atrophy (Bodine et al. 2001). We assume that the transcriptional differences of EDL and SOL muscles induced by a brief starvation indicate a presence of a complex adaptive program responsible for more pronounced acceleration of protein degradation in white muscles observed in response to various catabolic stimuli.

\section{Conclusions}

According to our knowledge, this study is the first that examined the effects of a brief starvation on amino acid levels and main parameters of protein metabolism in red (slow-twitch) and white (fast-twitch) muscles. The results demonstrate that red muscles have higher rates of protein turnover and may adapt better to a brief starvation when compared to white muscles. This phenomenon may play a role in more pronounced atrophy of muscles composed mostly by white fibers in aging and various muscle wasting disorders. Further studies are needed to examine the effects of prolonged starvation, in which changes in protein and amino acid metabolism are different when compared to short-term starvation.

\section{Conflict of Interest}

There is no conflict of interest.

\section{Acknowledgements}

This study was supported by the program Progres Q40/02 of the Charles University. Our thanks go to L. Sispera, PhD. for analysis of amino acids by HPLC and R. Fingrova and H. Buzkova for their technical support. 


\section{Abbreviations}

AMC, 7-amino-4-methylcoumarin; BCAA, branchedchain amino acids; CTLA, chymotrypsin like activity of proteasome; EAA, essential amino acids; EDL, musculus extensor digitorum longus; SOL, musculus soleus; FRPS, fractional rate of protein synthesis; MuRF-1, muscle-ringfinger-1; NEAA, non-essential amino acids.

\section{References}

BERGSTRÖM J, FÜRST P, NORÉE LO, VINNARS E: Intracellular free amino acid concentration in human muscle tissue. J Appl Physiol 36: 693-697, 1974.

BODINE SC, BAEHR LM: Skeletal muscle atrophy and the E3 ubiquitin ligases MuRF1 and MAFbx/atrogin-1. Am J Physiol 307: E469-E484, 2014.

BODINE SC, LATRES E, BAUMHUETER S, LAI VK, NUNEZ L, CLARKE BA, POUEYMIROU WT, PANARO FJ, NA E, DHARMARAJAN K, PAN ZQ, VALENZUELA DM, DECHIARA TM, STITT TN, YANCOPOULOS GD, GLASS DJ: Identification of ubiquitin ligases required for skeletal muscle atrophy. Science 294: 1704-1708, 2001.

EVANS WJ: Skeletal muscle loss: cachexia, sarcopenia, and inactivity. Am J Clin Nutr 91: 1123S-1127S, 2010.

FOLETTA, VC, WHITE LJ, LARSEN AE, LÉGER B, RUSSELL AP: The role and regulation of MAFbx/atrogin-1 and MuRF1 in skeletal muscle atrophy. Pflugers Arch 461: 325-335, 2011.

GARLICK PJ, MCNURLAN MA, PREEDY VR: A rapid and convenient technique for measuring the rate of protein synthesis in tissue by injection of [3H]phenylalanine. Biochem $J$ 192: 719-723, 1980.

GARLICK PJ, MALTIN CA, BAILLIE AG, DELDAY MI, GRUBB DA: Fiber-type composition of nine rat muscles. II. Relationship to protein turnover. Am J Physiol 257: E828-E832, 1989.

GOMES-MARCONDES MCC, TISDALE MJ: Induction of protein catabolism and the ubiquitin-proteasome pathway by mild oxidative stress. Cancer Lett 180: 69-74, 2002.

GOODMAN MN, MCELANEY MA, RUDERMAN NB: Adaptation to prolonged starvation in the rat: curtailment of skeletal muscle proteolysis. Am J Physiol 241: E321-E327, 1981.

GRAHAM JA, LAMB JF, LINTON AL: Measurement of body water and intracellular electrolytes by means of muscle biopsy. Lancet 2: 1172-1176, 1976.

GUPTA RC, MISULIS KE, DETTBARN WD: Activity dependent characteristics of fast and slow muscle: biochemical and histochemical considerations. Neurochem Res 14: 647-655, 1989.

HOLECEK M: The BCAA-BCKA cycle: its relation to alanine and glutamine synthesis and protein balance. Nutrition 17: 70, 2001.

HOLECEK M, SISPERA L: Glutamine deficiency in extracellular fluid exerts adverse effects on protein and amino acid metabolism in skeletal muscle of healthy, laparotomized, and septic rats. Amino Acids 46: 1377-1384, 2014.

HOLECEK M, SISPERA L: Effects of arginine supplementation on amino acid profiles in blood and tissues in fed and overnight-fasted rats. Nutrients 8: 206, 2016.

HOLECEK M, SPRONGL L, TILSER I: Metabolism of branched-chain amino acids in starved rats: the role of hepatic tissue. Physiol Res 50: 25-33, 2001.

HOLECEK M, SISPERA L, SKALSKA H: Enhanced glutamine availability exerts different effects on protein and amino acid metabolism in skeletal muscle from healthy and septic rats. JPEN $J$ Parenter Enteral Nutr 39: 847-854, 2015.

JEPSON MM, PELL JM, BATES PC, MILLWARD DJ: The effects of endotoxaemia on protein metabolism in skeletal muscle and liver of fed and fasted rats. Biochem J 235: 329-336, 1986.

KOOHMARAIE M, KRETCHMAR DH: Comparisons of four methods for quantification of lysosomal cysteine proteinase activities. J Anim Sci 68: 2362-2370, 1990.

KOVARIK M, MUTHNY T, SISPERA L, HOLECEK M: Effects of $\beta$-hydroxy- $\beta$-methylbutyrate treatment in different types of skeletal muscle of intact and septic rats. J Physiol Biochem 66: 311-319, 2010. 
KOVARIK M, MUTHNY T, SISPERA L, HOLECEK M: The dose-dependent effects of endotoxin on protein metabolism in two types of rat skeletal muscle. J Physiol Biochem 68: 385-395, 2012.

LOWRY OH, ROSEBROUGH NJ, FARR AL, RANDALL RJ: Protein measurement with the Folin phenol reagent. J Biol Chem 193: 265-275, 1951.

MCNURLAN MA, TOMKINS AM, GARLICK PJ: The effect of starvation on the rate of protein synthesis in rat liver and small intestine. Biochem J 178: 373-379, 1979.

MUTHNY T, KOVARIK M, SISPERA L, TILSER I, HOLECEK M: Protein metabolism in slow- and fast-twitch skeletal muscle during turpentine-induced inflammation. Int J Exp Pathol 89: 64-71, 2008.

MUTHNY T, KOVARIK M, SISPERA L, DE MEIJERE A, LARIONOV OV, TILSER I, HOLECEK M: The effect of new proteasome inhibitors, belactosin $\mathrm{A}$ and $\mathrm{C}$, on protein metabolism in isolated rat skeletal muscle. $J$ Physiol Biochem 65: 137-146, 2009.

RADILOVA H, LIBRA A, HOLASOVA S, SAFAROVA M, VISKOVA A, KUNC F, BUNCEK M: COX-1 is coupled with mPGES-1 and ABCC4 in human cervix cancer cells. Mol Cell Biochem 330: 131-140, 2009.

SAFRÁNEK R, HOLECEK M, SISPERA L, MUTHNÝ T: Aspects of protein and amino acid metabolism in a model of severe glutamine deficiency in sepsis. Ann Nutr Metab 50: 361-367, 2006.

STIREWALT WS, LOW RB, SLAIBY JM: Insulin sensitivity and responsiveness of epitrochlearis and soleus muscles from fed and starved rats. Recognition of differential changes in insulin sensitivities of protein synthesis and glucose incorporation into glycogen. Biochem J 227: 355-362, 1985.

TARDY C, AUTEFAGE H, GARCÍA V, LEVADE T, ANDRIEU-ABADIE N: Mannose 6-phosphorylated proteins are required for tumor necrosis factor-induced apoptosis: defective response in I-cell disease fibroblasts. $J$ Biol Chem 279: 52914-52923, 2004.

TIAO G, LIEBERMAN M, FISCHER JE, HASSELGREN PO: Intracellular regulation of protein degradation during sepsis is different in fast- and slow-twitch muscle. Am J Physiol 272: R849-R856, 1997.

TURINSKY J, LONG CL: Free amino acids in muscle: effect of muscle fiber population and denervation. Am J Physiol 258: E485-E491, 1990.

VANDESOMPELE J, DE PRETER K, PATTYN F, POPPE B, VAN ROY N, DE PAEPE A, SPELEMAN F: Accurate normalization of real-time quantitative RT-PCR data by geometric averaging of multiple internal control genes. Genome Biol 3: research0034.1-research0034.11, 2002.

WELLE S: Methods for studying protein metabolism in humans. In: Human Protein Metabolism. WELLE S (ed.), Springer-Verlag, New-York, 1999, pp 29-71.

WING SS: Control of ubiquitination in skeletal muscle wasting. Int J Biochem Cell Biol 37: 2075-2087, 2005. 